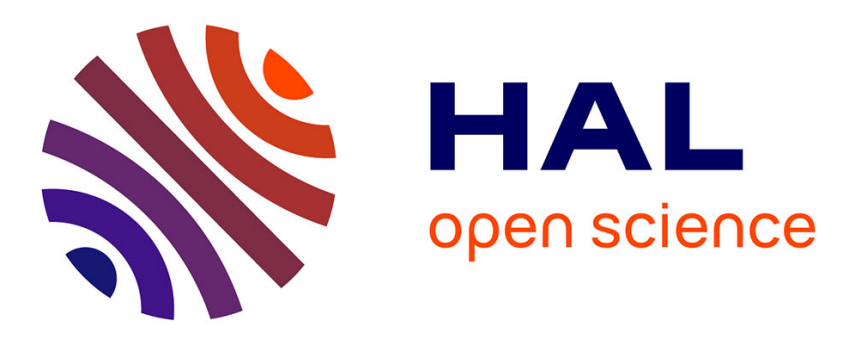

\title{
New versatile autonomous platforms for long-term geophysical monitoring in the ocean
}

Yann Hello, Jean-Yves Royer, Diane Rivet, Philippe Charvis, Manuk

Yegikyan, Olivier Philippe

\section{- To cite this version:}

Yann Hello, Jean-Yves Royer, Diane Rivet, Philippe Charvis, Manuk Yegikyan, et al.. New versatile autonomous platforms for long-term geophysical monitoring in the ocean. OCEANS 2019 MTS/IEEE, Jun 2019, Marseille, France. 10.1109/OCEANSE.2019.8867216 . hal-02398790

\section{HAL Id: hal-02398790 \\ https://hal.univ-brest.fr/hal-02398790}

Submitted on 8 Dec 2019

HAL is a multi-disciplinary open access archive for the deposit and dissemination of scientific research documents, whether they are published or not. The documents may come from teaching and research institutions in France or abroad, or from public or private research centers.
L'archive ouverte pluridisciplinaire HAL, est destinée au dépôt et à la diffusion de documents scientifiques de niveau recherche, publiés ou non, émanant des établissements d'enseignement et de recherche français ou étrangers, des laboratoires publics ou privés. 


\section{New versatile autonomous platforms for long-term geophysical monitoring in the ocean}

\author{
Yann Hello \\ UMR Geoazur \\ Univ. Côte d'Azur, IRD, CNRS, OCA \\ Sophia Antipolis, France \\ yann.hello@geoazur.unice.fr \\ Philippe Charvis \\ UMR Geoazur \\ Univ. Côte d'Azur, IRD, CNRS, OCA \\ Sophia Antipolis, France \\ philippe.charvis@geoazur.unice.fr
}

\author{
Jean Yves Royer \\ Laboratoire Géosciences Océan \\ CNRS \& Université de Brest \\ Brest, France \\ https://orcid.org/0000-0002-7653-7715 \\ Manuk Yegikyan \\ OSEAN-SAS \\ Le Pradet, France \\ manuk.yegikyan@osean.fr
}

\author{
Diane Rivet \\ UMR Geoazur \\ Univ. Côte d'Azur, IRD, CNRS, OCA \\ Sophia Antipolis, France \\ diane.rivet@geoazur.unice.fr \\ Olivier Philippe \\ OSEAN-SAS \\ Le Pradet, France \\ olivier.philippe@osean.fr
}

\begin{abstract}
Long-term monitoring of the ocean, for instance its seismic activity, remains a technical and a financial challenge. Despite technological advances in reducing the size and consumption of electronic components, in providing powerful energy through Lithium batteries, and in reducing the size of sensors, the new generation of stand-alone instruments such as Ocean Bottom Seismometers (OBS) cannot be deployed on average for more than a year on the seafloor and provide access to their data only upon their recovery. Any long-term monitoring thus implies multiple cruises and redeployments. Permanent observatories with real-time access to data require ambitious cabled-to-shore sensors and infrastructures. Here we propose an alternative solution bridging the gap between these two endmembers, consisting of multi-parameter platforms for seafloor (MUG-OBS) or water-column (HYDROBS) observations, and offering a lifespan of four years and an access to the collected data through data-shuttles releasable on demand from a surface ship.
\end{abstract}

Keywords- deep-sea observatory, seismicity, water-column observatory, hydroacoustics, pressure sensors

\section{INTRODUCTION}

\section{A. State of the art in monitoring seismic activity}

Monitoring the seismic activity at sea is a major issue for understanding the dynamics of active plate boundaries, particularly in the vicinity of coastal areas where devastating tsunamigenic earthquakes may occur (e.g. 2010 Maule, Chile, 2011 Tohoku, Japan, 2016 Pedernales, Ecuador). As for landbased seismometer networks, the most efficient way to implement such monitoring is to deploy real-time wired networks of broadband ocean-bottom seismic sensors, as the Neptune observatory off Canada [1] or DONET array off Japan [2]. However, the high costs of such infrastructures prevent any widespread deployment worldwide.

A more conventional and cost effective approach consists in repeatedly deploying arrays of autonomous ocean-bottom seismometers (OBS) as, for instance, in the Amphibious Cascadia Initiative (four 1-year deployments [3]), the Obsismer program in the French Lesser Antilles (eight 6month deployments) [4] or the Osisec program in Ecuador (four 6-month deployments) [5]. The autonomous OBSs are then recovered with a ship, directly or with a remotely operated vehicle (ROV). This approach is still costly since it requires multiple cruises and human resources, and the data are not accessible until the OBSs are recovered.

Another strategy is to use drifting sensors, such as the Argo and Mermaid floats [6,7], which record the acoustic waves generated by undersea earthquakes in the water column. Such sensors can be spread over large areas, but the data are not the actual 3-component seafloor motions. In addition, they are transmitted in a very limited amount (satellite transmission with limited power supply) and the sensor distribution is poorly controlled.

Recently, the use of optical fibers (OF) as seismo-acoustic sensors opened new possibilities. Strain induced by seismic waves in an optical fiber generates back-scattering of the injected laser beam. The method known as Distributed Acoustic Sensing (DAS) exploits this effect to turn OF cables into dense linear seismic arrays, with high-frequency $(1 \mathrm{kHz})$ acoustic measurements with a metric spacing. This technology, commonly used in the oil and gas industry, has only recently revealed its full potential for seismological and environmental applications [8,9], and has not yet been implemented in a marine environment. However, the need for a light source and large data-storage facilities probably means cabled-to-shore facilities.

Instrumenting the oceans thus remains a challenge at hand. With the advent of low-consumption electronics, innovative batteries and broadband satellite-data transmission, it is now possible to design autonomous platforms with a greater autonomy. In addition, new needs for multi-disciplinary observation have emerged, as demonstrated by the large permanent networks (DONET, Neptune, EMSO), in order to address major inter-related scientific issues, dealing with ocean or plate-boundary dynamics, human pressure, or the surveillance of various resources and natural hazards (earthquakes, tsunamis, submarine landslides).

In this scope, we have developed autonomous multichannel systems, with an autonomy of up-to 4 years (depending on the type and number of connected sensors) allowing the acquisition of different seismic and environmental parameters. These systems can be deployed on the sea-floor or in the water column. The data are logged in shuttles that can be retrieved on demand from a surface ship, until the final recovery of the main system.

The seafloor version of this platform is a Multi-parameter Geophysical Ocean Bottom System or MUG-OBS and is a free-falling instrument operating at up to a $6000 \mathrm{~m}$ depth. The installation of the seismic sensor is monitored by acoustic commands from the surface. With an autonomy of 4 years (with a broadband seismic sensor), it is a perfect tool to monitor large seismic events, background seismic activity and aftershock distribution among other applications. A simplified version of MUG-OBS, without shuttles, is a state-of-the-art 
ocean-bottom seismometer called MANTA, dedicated to short-term seismic monitoring (see last section).

The water-column version of this platform, called HYDROBS for hydroacoustic observatory, can be equipped with hydrophones, CTD or ADCP, to monitor the acoustic noise, and physical or chemical properties of the ocean.

The main feature of both platforms is to hold from 3 up to 6 shuttles where the logged data are duplicated and which can be retrieved on demand from a surface ship. Both platforms share the same acquisition system, A/D converters, precise clock and adjustable storage capacity. Acoustic communications from the surface to the platforms can be used to get its health bulletin (e.g. storage and battery levels) or for specific tasks such as deploying the seismometer at installation, launching the shuttles, or preparing and releasing the platform for its final recovery.

\section{B. A brief history of $O B S s$}

The first OBSs appeared in the 1970s and were designed by US research institutions (WHOI, SIO, University of Texas). These instruments were analog, recording data on magnetic tapes, and later used the first commercially available micro-processors (e.g. Z80, RCA 1802, CF1, CF2, ...). They were relatively energy-efficient, but had limited storage capacity and inaccurate clocks.

The sensor was a vertical geophone with, for some, 2 horizontal components. Their purpose was mainly wide angle refraction experiments or local earthquake monitoring. The sensors were encapsulated in the pressure case, some of them were mounted on a cardan shaft to compensate the tilt of the instrument on the seafloor. The instrumental response was a function of the geophone mount in the pressure case (screwed to a stainless-steel frame, glued to a glass sphere), of the pressure case fixture on the disposable anchor, and of the coupling of the anchor frame with the sea bottom. The latter relied on the OBS total weight in the water, the frame size and shape, and on the seafloor type. It was thus quite difficult to characterize the instrumental response of each deployed OBS. In addition, the 3 components of the geophone were generally not oriented.

Modern OBSs are low power, with high precision clocks (10-7 or better), sensitive to finer motions, and have 4 channels (3-component geophone and a hydrophone). They are divided in two categories: short period and long period OBSs. Short period OBSs are sensitive to high frequency motions suitable to detect small and local earthquakes and to study the upper layers of the crust. Their autonomy ranges from 2 weeks to 6 months. Long period OBS are sensitive to a broad range of motions up to $60 \mathrm{~s}-120 \mathrm{~s}$ and capable of detecting distant earthquakes. They can operate up to 12 months.

In an attempt to obtain a better coupling, the geophones are now integrated in a container separated from the main structure of the OBS and connected by a cable. The coupling then relies only on the size of the surface contact between the sensor and the seafloor.

Guralp and Nanometrics companies came to the rescue of seismologists with sea-bottom seismometers directly pluggable to permanent cabled-installations such as Donet, Neptune, or EMSO-Antares. These sensors, initially selfleveled, are now freed from this constraint. The new Trillium compact and Radian OBS triaxial broadband instrument are auto-leveled in all orientations, and provide North geographical orientation, tilt and other useful parameters. The Radian also integrates an accelerometer and the digitizer performs a force feedback servo-control. The cut-off frequency is also programmable. These two companies together with help of academic institutions now propose their own complete OBS systems. Comparative studies on realtime cabled sensors have proved that the best coupling and noise reduction is obtained when the sensor is buried into the sediments. When such operation is not possible, as in a deepsea deployment, the seismometer should be shielded by a cover to prevent noise from convective or bottom currents.

Modern OBSs use stable clocks (even atomic clocks to the cost of high-power consumption), fast data-recovery and easy set-up before deployment. Furthermore, greater life-times of lithium batteries and more reliable integrated electronic components provide autonomous OBSs with improved capabilities for wide range, long and continuous monitoring.

The following presents the MUG-OBS concept as an alternative solution between real-time cabled installations and short to broadband period OBSs.

\section{THE MUG-OBS CONCEPT}

The concept of a Multi-parameter Geophysical Ocean Bottom System (MUG-OBS) stemmed from the needs of the "marine" seismology community who was looking for a marine seismometer meeting the standards of land-based seismometers (broadband, low-noise) and limiting the costs and constraints inherent to deep-sea deployments (due to multiple cruises and re-deployments).

\section{A. MUG-OBS Main innovations}

The innovation in the MUG-OBS concept is several folds: - The ability to retrieve the data on demand, through releasable shuttles (up to 6);

- Its long-term autonomy (up to 4 years);

- The frame design;

- The seismometer installation procedure;

- Many "little" practical details learned from 40 years of OBS experience;

- In addition to an acoustic communication system to set-up, control, and release the instrument, and the integration of GPS/AIS and/or Iridium communication to recover the shuttles or the instrument.

The data are accessible on demand at any time (e.g. every 6-months or after a seismic crisis) by recovering one of the 6 data-shuttles. The shuttles are released from the surface by acoustic command. The data are duplicated every day from the main acquisition system to two shuttles, for redundancy ( $\mathrm{N}$ and $\mathrm{N}+1$ ). Prior to its release, the shuttle clock is synchronized with the master clock. When surfacing, the shuttle clock self-synchronizes with the GPS time and stores the measured clock drift. In remote areas, shuttles can be released automatically at predefined times and a seismic event bulletin transmitted by Iridium satellite communication. Selected data can also be recovered by two-way Iridium satellite communication. Shuttles are 13" glass sphere that can be recovered by any small boat of opportunity, capable to receive the GPS/AIS signal emitted by the shuttle. The shuttle can be switched off without opening (magnet switch). This shuttle system thus offers a significant improvement relative to multiple deployments of short-term OBSs. The 
seismometer remains at the same location with the same coupling to the seafloor for several years; this feature is particularly critical for monitoring slow sleep events. But most of all, there is no need for repeated cruises with a dedicated research vessel and an OBS specialist to recover the shuttles (i.e. recovering 6 shuttles avoids 6 redeployments of a classical OBS).

The long autonomy results from a low-power consumption acquisition system, an optimized data management (acquisition and duplication) together with powerful batteries. The main acquisition system is based on a very-low-power Cortex M4 microprocessor and A/D 32-bit convertor. Time is given by a $10^{-8}$ real-time clock and data are stored in SD cards. Lithium batteries provide 4 years of autonomy (252 DD Cells assembled in 7 packs delivering $23 \mathrm{kWh} @ 0^{\circ}$ Celcius). Acoustic communication with the surface-ship allows a control over all functionalities during deployment or later for evaluation visits. A complete health bulletin (sensors and components checking, storage and battery levels) can be retrieved at any time on demand. Settings and diagnostics are user-friendly from a web-page server.

The frame of MUG-OBS is made of non-corrosive materials, polyethylene, peek, nylon, and pressure cases are either in glass or titanium (Fig. 1). Buoyancy is ensured by syntactic foam bars. The steel disposable weight anchor, which sinks the instrument to the bottom of the ocean, is protected by anodes. The whole structure is shaped to resist trawling, which is not the case for most existing OBS. This is particularly useful for long-term deployment close to shore within a fishing depth range of $2000 \mathrm{~m}$ (e.g. in the vicinity of a subduction zone). The complete system can be mounted and dismantled into pieces to facilitate its transportation.

Broadband sensor installation at the bottom of the sea generally requires an ROV. The best coupling for a best dataquality is obtained by burying the sensor unit, or if not possible, by covering it with a dome-shaped shelter to protect the sensor from current convections. For MUG-OBS the structure itself acts as a protecting dome. The sensor is suspended in the central well formed by the skeleton of the structure (4 panels assembled by tenon and mortise). Two flap panels, opened during the descent, close automatically when the instrument reaches the bottom, encasing the sensor in a box (4 walls and a top lid). Pressure measurements will tell MUG-OBS that it has reached the bottom of the sea. If the tilt of the MUG-OBS frame is within some predefined limits, the sensor will drop automatically from $20 \mathrm{~cm}$ above the ground. If the tilt exceeds these limits, one can either force the seismometer installation or release and recover the entire system and redeploy it in another site. The sensor well, $80 \mathrm{x}$ $80 \mathrm{~cm}$ wide, gives enough space to ensure that the sensor is not in contact with the polyethylene frame but only with the ground for good coupling. The seismometer coupling mode proposed in MUG-OBS has become a standard for fee falling OBSs.

MUG-OBS (Fig. 2) is tied to the corners of the disposable square-shaped anchor by four Dynema ropes gathered together on top of the unit to the main release system, away from the sea-bottom and sediments, where biological activity can boost natural electrolysis and corrosion. A tensor helps adjusting the Dynema tension to ensure a good holding of the whole structure. A specific acoustic signal, sent from the surface, will activate the release system; then MUG-OBS will rise from the seabed lifted by the 200 -liter surge produced by syntactic foam. Eight carbon spring slats provide each an additional thrust of $25 \mathrm{~kg}$ to unstick the MUG-OBS from surficial sediments in which it may have been buried over time.

When surfacing for recovery, as for the shuttles, the clock drift is automatically measured as soon as a GPS signal is acquired by the main unit. The station GPS location is then sent by AIS, which can be displayed on a dock navigation system. Geographic coordinates can also be sent through the Iridium satellite network, in case of an inadvertent release from the anchor; the users will then be warned by a text/e-mail message.

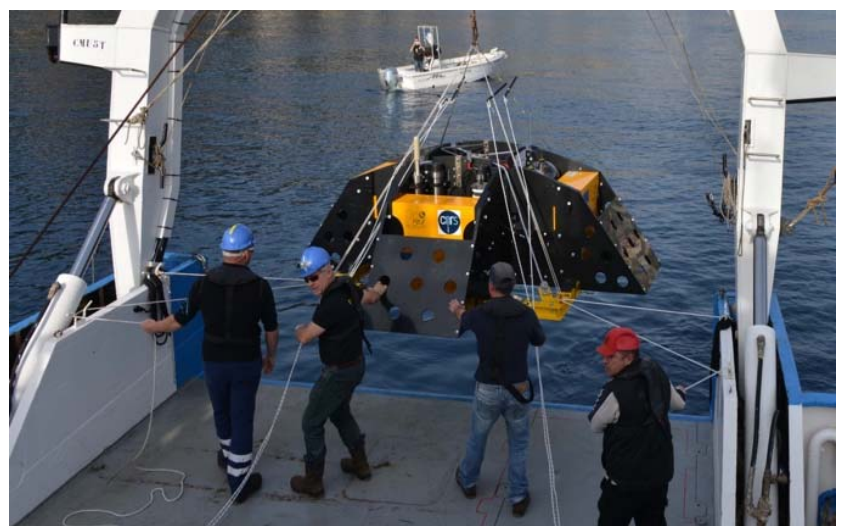

Fig. 1. Deployment of a MUG-OBS (2.9m x 2.9m x 1m, for a weight in Air of $1.5 \mathrm{t}(3307 \mathrm{Lb}))$. The frame is made of non-conductive material (syntactic foam, polyethylene, glass and titanium cases) and shaped to resist trawling.

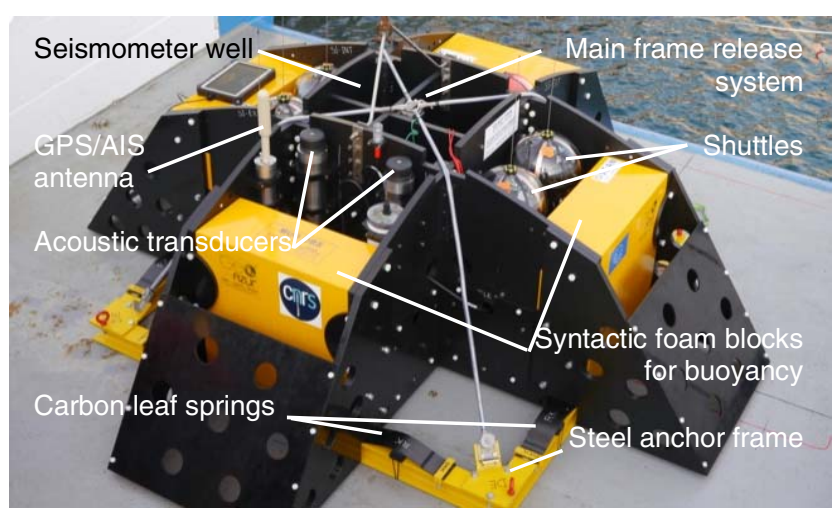

Fig. 2. The disposable weight anchor is made of steel with anodes. The MUG-OBS is tied to the anchor by four Dynema ropes joined together to the release system. When released, MUG-OBS rises by its own positive buoyancy $(200 \mathrm{~kg})$. Eight leaf springs produce an additional 8 x $25 \mathrm{~kg}$ thrust to help its take off from the sea-bottom.

\section{B. Message in a bottle}

The shuttles are encapsulated in a 13" glass sphere (Fig. 3) They use the same CPU board and clock as the main station. Communications and data transfer between the main acquisition system and the shuttles are Digital Inductive through water. This wireless technique gives great transfer rate performance at $1 \mathrm{Mbit} / \mathrm{s}$, even in muddy water. Data are copied from the main station to shuttle " $N$ " every day at 00:00 and immediately after to shuttle " $\mathrm{N}+1$ " for redundancy. Shuttles can be released anytime by acoustic command. When this command is received, the main station synchronizes the shuttle clock against its own clock and then releases the shuttle. When surfacing, the shuttle looks for a GPS signal and calculates the clock drift against GPS time. This is a way to monitor the main-clock drift at every shuttle recovery. It 
assumes that the temperature of the main station and shuttles is constant at depth, and that the shuttle synchronizes itself before balancing with the sea-surface temperature. This automatic process allows any non-specialist to handle a shuttle recovery. Furthermore, it alleviates the need for an extremely accurate main-clock to precisely time the MUG-OBS records over 3-4 years, since the clock-drift can be measured at every shuttle recovery, and thus saving some power supply. The AIS system facilitates the shuttle recovery and provides confidence and comfort to the operators. Time for recovery is also made shorter.
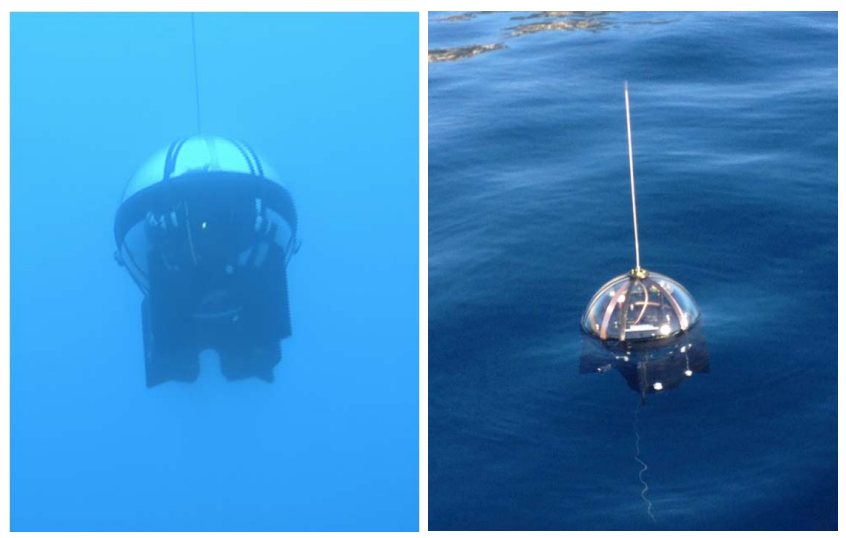

Fig. 3. Data shuttle on its way to the surface and at sea-surface. The electronic, encapsulated in a 13" glass sphere, is designed around a Cortex M4 microprocessor, memory boards (SD cards), an internal clock, a flash light, a GPS and AIS to track the shuttle on the surface, and is powered by a Lithium battery. The shuttle clock synchronizes with the main clock of the system prior to its release, and synchronizes itself as soon as a GPS signal is received at sea-surface. This enables monitoring the clock-drift of the main acquisition clock at every shuttle recovery over the 3 years of the MUG-OBS deployment.

\section{Technical details}

MUG-OBS consists of different modules integrated into the polyethylene frame.

1) The main acquisition case is a subassembly with its own power supply, independent of all other MUG-OBS modules, and manages all the incoming data from various sensors (Fig. 4). The Management/Power module is equipped with an EPLD microcontroller that manages communications with the Battery Containers, Localization Container and the CAN Acquisition Module. This management includes the data acquisition and their transfer to the main mass-memory of the MUG-OBS, and to the mass-memory of the shuttles. The Management/Power module also provides and controls the power supply to the following parts:

- TRILLIUM seismic sensor and accelerometer;

- HTI-90U hydrophone;

- SCRIPPS Differential Pressure Gauge;

- Paroscientific absolute pressure sensor;

- Ultra-stable SEASCAN clock;

- CAN Acquisition Module.

2) The batteries are stored in three containers of the same size as the container acquisition. In total, MUG-OBS uses 252 CSC93 ELECTROCHEM batteries. These containers are located at the base of the mechanical structure of the MUGOBS in order to balance the structure and provide a good stability.

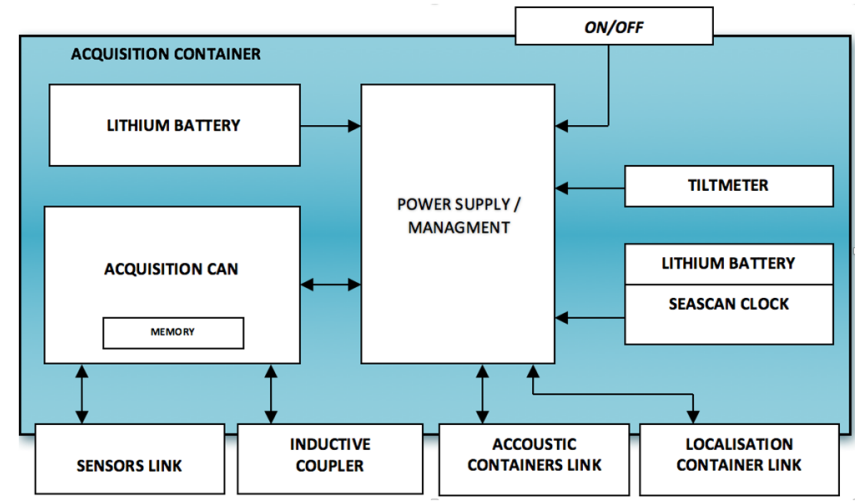

Fig. 4. Schematic diagram of the acquisition container.

3) The 6 shuttles are subassemblies allowing the MUGOBS to return some of its data to the surface. Shuttles can store data for two years, they are powered by their own lithium battery ( 2 packs of DD cells delivering $1.5 \mathrm{kWh} @ 00^{\circ} \mathrm{C}$ ) and activate when surfacing a GPS/AIS system and a strobe light for recovery.

4) The acoustic containers are subassemblies carrying out all the acoustic communications between the MUG-OBS and the surface control Dock. The acoustic containers are duplicated for security purposes. This include all electronics, transducer, connectors and batteries. From the surface, it is possible to communicate independently with either acoustic system by selecting its coding and acoustic frequencies. Their functions and their operations are identical.

5) The localization container encloses all the systems to locate the MUG-OBS at sea-surface, by AIS and Iridium. It includes a radio antenna for AIS module transmissions, a unique helical antenna for IRIDIUM module transmissions and GPS.

6) Inductive couplers (one per shuttle) are waterproof electromagnetic wireless communication interface between the shuttles and the MUG-OBS station (data duplication, clock synchronization).

7) The sensors:

- A TRILLIUM seismic sensor: a very low-power seismic sensor designed for immersions of up to 6,000 meters.

- A three-axis accelerometer mechanically coupled to the seismic sensor, and a tiltmeter.

- A differential pressure sensor (from the Scripps Institution of Oceanography) measures changes in the water column above the MUG-OBS.

- An "absolute" pressure sensor (Paroscientific-4000).

- A hydrophone (HTI-90U) sensor for measuring the acoustic noise.

8) The SEASCAN clock has a $10^{-8} \mathrm{~s} / \mathrm{s}$ drift. The GPS provides a precise time signal at $100 \mathrm{~ns}$ and the initial synchronization constraint of $100 \mu$ s is maintained by the GPS PPS signal.

- This clock is powered by the CPU voltage from a dedicated permanent power supply. If necessary, a spare battery can power this clock for more than a year.

- The files saved on the MUG-OBS SDHC mass-memory are time stamped by this real-time clock (the file name dates the first sample of the file).

- Time stamps are also sent to the shuttles prior to their release to surface. 
- This clock controls a timer that triggers, every 24 hours, the transfer to a shuttle of the data collected during the previous 24 hours.

- The CAN acquisition module consists of two electronic boards, each of which can manage 4 analog channels. The sampling of all analog channels is synchronized with this ultra-stable time base. Typically, the seismic accelerometers and hydrophone sensors are sampled at 100 $\mathrm{Hz}$, DPG $4 \mathrm{~Hz}$, Paroscientific $1 \mathrm{~Hz}$ and the other sensors every 10 minutes (tilt, temperature, pressure, ...).

9) There is a "back-up clock" to release the MUG-OBS at a predefined date (to be programmed prior to deployment). This independent clock is located in the battery container.

10) MUG-OBS has three mechanical release units:

- The main release unit will cut the Dynema ropes that tie the main frame to the disposable anchor, allowing the MUGOBS station to rise to the sea-surface.

- A set of 6 separate release units will cut the nylon strings holding the shuttles onto the main frame and let them rise to the sea-surface.

- A temporized release system drops the seismic sensor to the ground, depending on the tilt of the frame on the seafloor.

The first two release systems are controlled by acoustic remote controls from the surface-ship. For safety, the main release unit of the MUG-OBS can also be activated automatically on a pre-programmed date (see back-up clock). Mechanical release systems proved more reliable than usual burn-wires, commonly used in OBSs, especially for long-term deployment during which natural electrolysis and corrosion may be strongly accentuated.

\section{PERFORMANCE OF THE MUG-OBS SYSTEM}

We tested a MUG-OBS equipped with a Nanometrics Trillium 120s, a tri-axial accelerometer, a differential and absolute pressure gauge, and a hydrophone, offshore Nice at $2450 \mathrm{~m}$ depth from November 2016 to January 2019 (Fig. 5). During the experiment, many local earthquakes were recorded as well as a distant large teleseismic event $(\mathrm{Mw}=8.1)$ that occurred 8 September 2017 south of Mexico. The quality of the seismic acquisition was estimated from both the seismic noise and local and distant earthquakes waveforms. The MUG-OBS data were compared with records from 3 near-by seismological stations: ASEAF a permanent offshore broadband cabled-seismometer, AA08 a temporary shortperiod ocean-bottom seismometer, TURF a permanent onland station from the RESIF network (Fig. 5).

\section{A. Noise sensitivity}

The seismic noise can be evaluated with a probability density function, following the method proposed by McNamara and Buland [10] (Fig. 6). For the vertical component, MUG-OBS provides a very good sensitivity in the whole period range being in average less than $20 \mathrm{~dB}$ higher than the New Low Noise Model [11]. The sensitivity of the MUG-OBS is comparable to that of ASEAF for the vertical component, which was carefully installed using a ROV. Both OBS display higher noise amplitude than TURF installed onland in a borehole in a very quiet region. For the horizontal components, the response of the MUG-OBS is similar to the one observed for the vertical component for short periods (< $5 \mathrm{~s})$. However, at longer periods $(>5 \mathrm{~s})$ the power spectral density of the noise slightly increases. This effect, common on seafloor, is probably due to the interaction of the ocean water mass movement and tilt of sea floor.

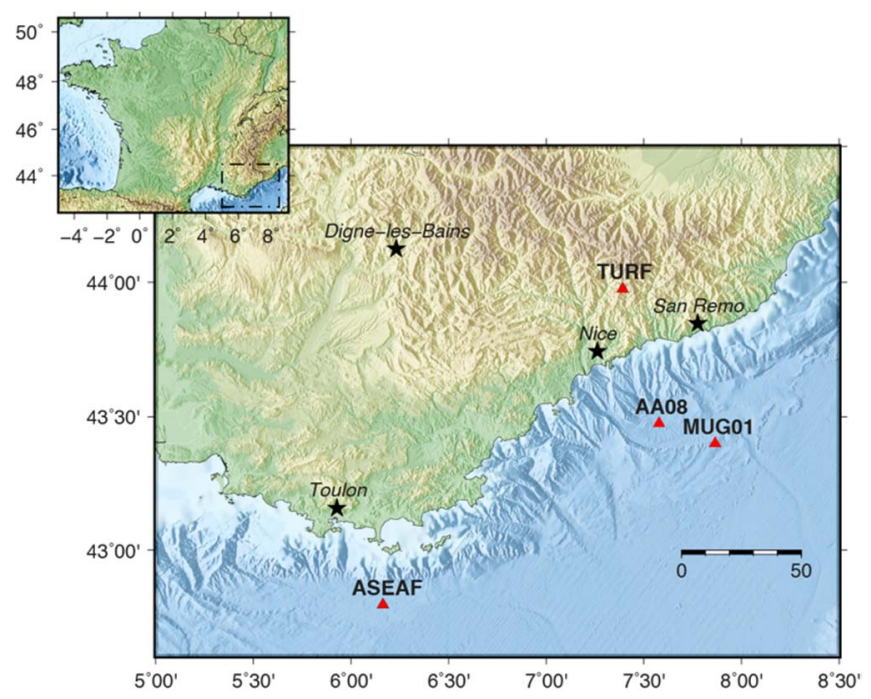

Fig. 5. Maps of the Ligurian coast. Triangles indicate seismic stations. ASEAF is a permanent off-shore broadband cabled seismometer, AA08 a temporary short-period ocean-bottom seismometer, TURF a permanent broadband on-land station of the RESIF network. MUG01 (MUG-OBS) is located 60 kilometers offshore Nice.

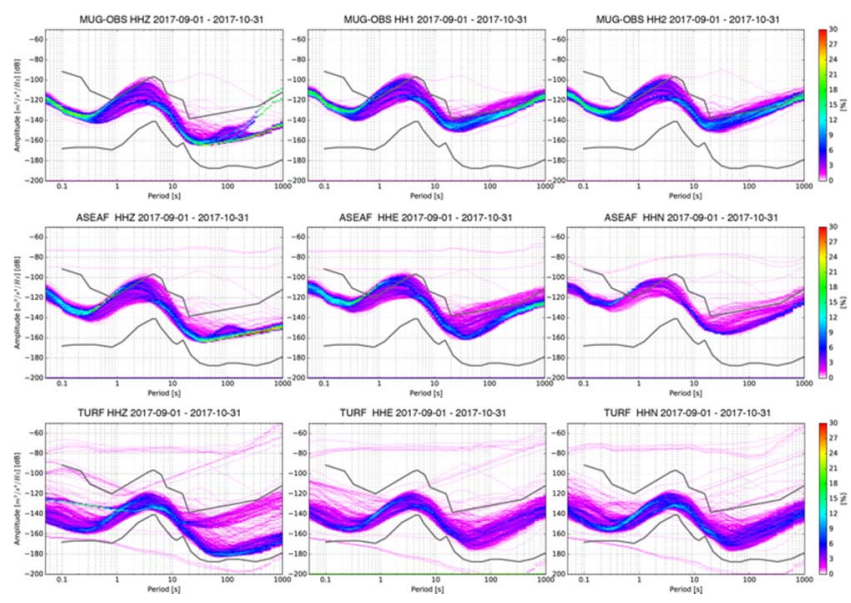

Fig. 6. Probability density functions (PDFs) for the vertical and the two horizontal components of broadband seismic sensors: Trillium 120s for MUG-OBS (top), CMG 3T 360s for ASEAF cabled OBS (middle) and Trillium 240s for TURF (bottom). Color scale represents the probability in percent. Black curves show the New Low-Noise Level (NLNM) and the New High-Noise Level (NHNM) [11].

\section{B. Broadband seismic records of a teleseismic earthquake}

During this 430-day experiment, MUG-OBS recorded a $\mathrm{Mw}=8.1$ teleseismic earthquake (8 Sept. 2017), located south of Mexico (Fig. 7). With a low noise-level on both the vertical and horizontal components, the seismic signal is well recovered. Waveforms recorded by the MUG-OBS and ASEAF are very similar in all components (Fig. 7 and 8). Both short-period volume waves and longer-period surface waves are well retrieved. However, for both OBSs, the highfrequency noise-level is higher than that from the TURF onland station which is not subject to local ocean noise (Fig. 9). For such a broadband seismic event, a standard short-period sensor ( $L 22-E$ of AA08 OBS) only records the direct P-waves (Fig. 10). 


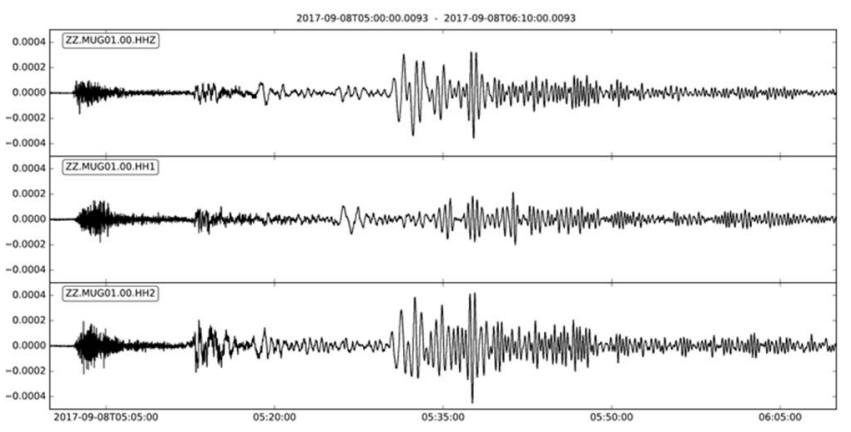

Fig. 7. $M w=8.1$ Mexico teleseismic event ( 8 September 2017) recorded by the MUG-OBS broadband seismic sensor.

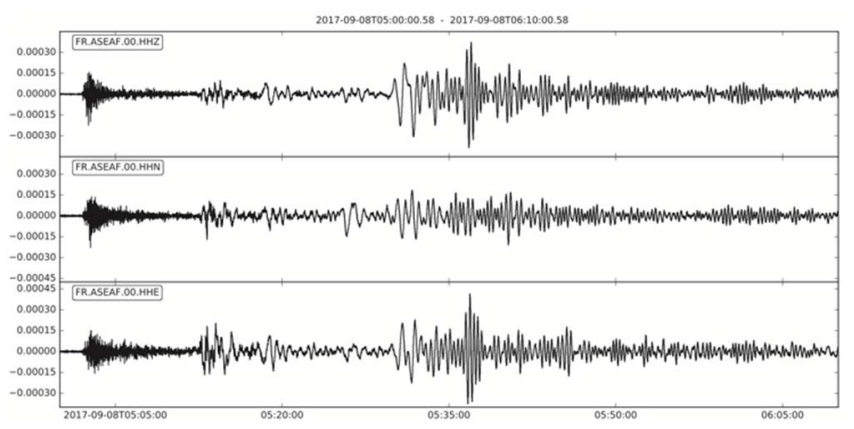

Fig. 8. $M w=8.1$ Mexico teleseismic event ( 8 September 2017) recorded by the broadband cabled $A S E A F$ seismometer.

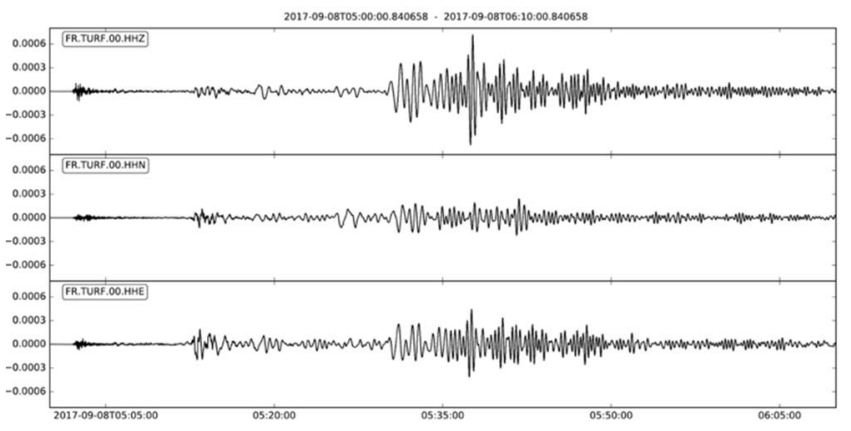

Fig. 9. $M w=8.1$ Mexico teleseismic event ( 8 September 2017) recorded by the on-land TURF seismometer.

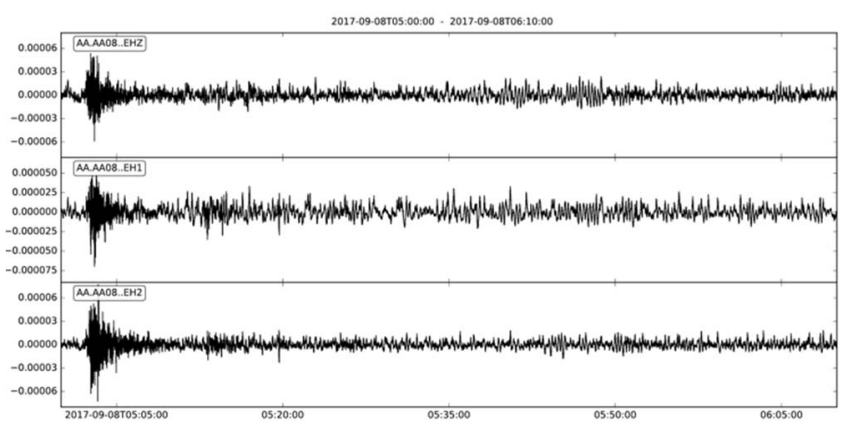

Fig. 10. $\mathrm{Mw}=8.1$ Mexico teleseismic event ( 8 September 2017) recorded by the short-period ocean-bottom $A A 08 O B S$ seismometer.

\section{Local Earthquake}

Many local and regional earthquakes were recorded during the deployment. Figure 11 shows recorded waveforms from a shallow $\mathrm{ML}=2$ earthquake located $30 \mathrm{~km}$ east of the MUGOBS. Due to the very low noise level of MUG-OBS, small amplitude seismic waves are well recovered on the vertical and horizontal components. The amplitude on the vertical component is lower than the horizontal ones because the earthquake is shallow.

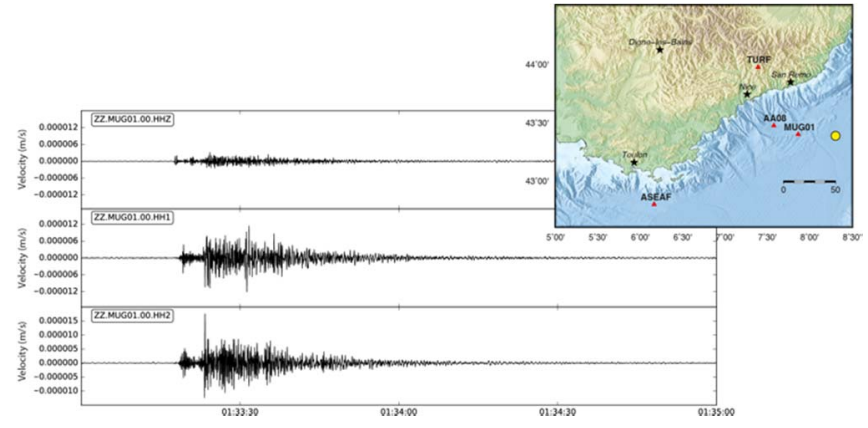

Fig. 11. Three components seismic signals of the 17 August $2017(\mathrm{ML}=2)$ local earthquake in the Ligurian Sea recorded by the MUG-OBS seismometer. The epicenter is shown by a yellow circle.

\section{TOWARD A MULTIDICIPLINARY PLATFORM}

Oceanographers and hydro-acousticians are confronted with the same difficulties as seismologists for monitoring physical or acoustic properties in the water-column over long periods of time, particularly in remote areas. For this purpose, instrumented mooring lines are generally repeatedly deployed and recovered, to access the data and to refurbish the sensors and mooring lines. It thus requires multiple cruises with a research vessel able to handle mooring deployments and a qualified staff to maintain the lines and instruments. The MUG-OBS concept, with data shuttles, a long autonomy (in power and data storage) and a low-power multichannel acquisition system, could certainly meet the needs of these communities. In 2020, MUG-OBS will be tested again off Nice with an additional CTD sensor (conductivity, temperature, depth).

But beyond this simple test, the concept was adapted to instrument a mooring line. To reduce its size and weight, the system was modified to hold 3 shuttles and handle 4 channels. The mooring version of the MUG-OBS platform is called HYDROBS, standing for hydroacoustic observatory.

\section{A. HYDROBS: a versatile long-term data-logger with shuttles for monitoring the water column.}

The HYDROBS platform has two main components: a data logger, able to communicate with a surface-ship, and three shuttles, releasable on demand to retrieve the data. It is mounted on a classical mooring line, with an expandable weight at the sea-bottom to maintain the mooring, a standalone acoustic release to free the mooring line for recovery, a line adjustable to the water depth, and an immerged buoy, holding the acquisition system and shuttles. The buoy maintains all sensors at a constant depth and will bring the mooring line to the surface for recovery.

As in MUG-OBS, the data logger comprises a low-power microprocessor Cortex M4, A/D-32 bit convertors, a $10^{-8}$ precision real-time clock and large SD card storage. Lithium batteries provide 3-4 years of autonomy depending on the sampling rates. Acoustic communications with the surfaceship provide control over all functionalities at deployment and a health bulletin on demand. The 3 shuttles, encapsulated in 13 " glass spheres, have the same CPU board and clock as the main station (Fig. 12 right).

All the components are enclosed in a polyethylene nacelle fixed above a buoy made of syntactic foam. The main acquisition system and batteries are encapsulated in a titanium cylinder ( $96 \mathrm{~cm} \times 20 \mathrm{~cm}$ diameter), located inside the buoy (stack of rings). The whole structure is held together by four 
titanium rods linking a top and bottom frames where the mooring line can be fixed (Fig. 12 left).

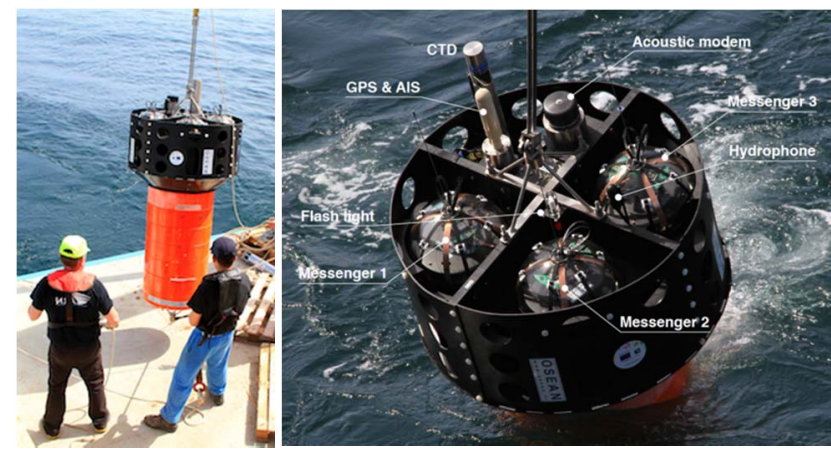

Fig. 12. HYDROBS platform and details of the nacelle at deployment

The data logger has 4 channels and can thus sample and digitize analog data from 4 sensors, or log data from standalone sensors mounted on the mooring line through serial connections (CTD - Conductivity Temperature Depth, ADCP - Acoustic Doppler Current Profiler, chemical analyses, ...). The data logger has also some internal sensors: humidity, temperature, pressure (depth), and tri-axial inclinometers.

The shuttles are identical to the MUG-OBS shuttles (GPS/AIS, strobe light) and are managed in the same way: duplication of the data every $24 \mathrm{~h}$ through magnetic induction, clock synchronization prior to their release, automatic selfsynchronization when surfacing.

In essence, the HYDROBS system is multipurpose:

- Long-term acoustic monitoring of the ocean (Fig. 13): lowlevel seismic activity along mid-oceanic ridges and submarine volcanoes ( $\mathrm{T}$-waves), seasonal presence and migration patterns of baleen whales, iceberg calving or dislocation, sea-state, oceanic background sound level, anthropogenic sounds (ship traffic, seismic shots), ...

- Long-term monitoring of physical parameters in the water column: CTD, ADCP, chemical sensors, ...

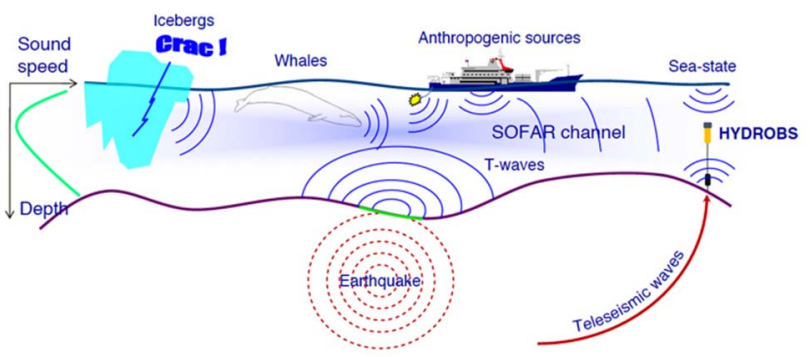

Fig. 13. Application of HYDROBS for monitoring acoustic noises propagating in the SOFAR (sound fixing and ranging) channel.

\section{B. Performance of the HYDROBS platform}

HYDROBS was successfully tested for two months, from April to early June 2018, at the same site off Nice as MUGOBS (Fig. 5). The platform (and sensors) was immerged at $800 \mathrm{~m}$. For this experiment, it was equipped with a HTI-90U hydrophone and a stand-alone CTD logger (Seabird SBE 37). The acoustic data were sampled at $250 \mathrm{~Hz}$, and the CTD data were logged through a serial connection every 10 minutes. The three shuttles were successfully recovered prior to the final recovery.
Figures 14 to 16 show examples of acoustic data recorded by HYDROBS (earthquake and fin whale) and the monitoring of the data-logger internal sensors.

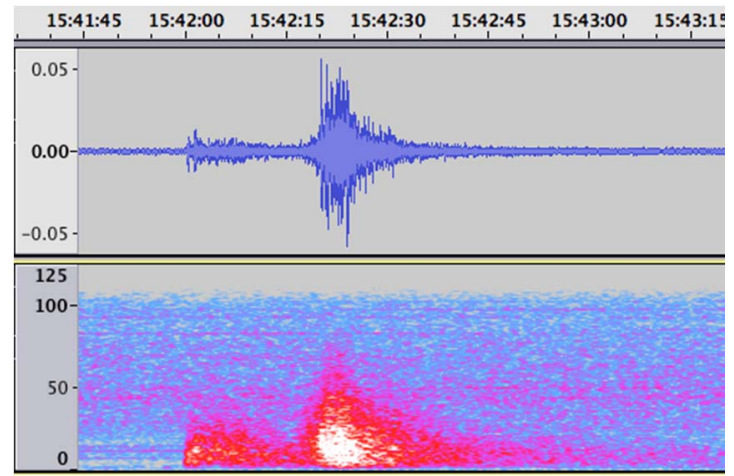

Fig. 14. Acoustic time signal and spectrogram of a $\mathrm{ML}=2.4$ local earthquake that occurred 50km from HYDROBS (29 April 2018). On can see the P- and $\mathrm{S}$-wave arrivals at $15 \mathrm{~h} 42$ (converted at the foot of the HYDROBS mooring, see Fig. 13) and the T-wave arrivals 20s later.

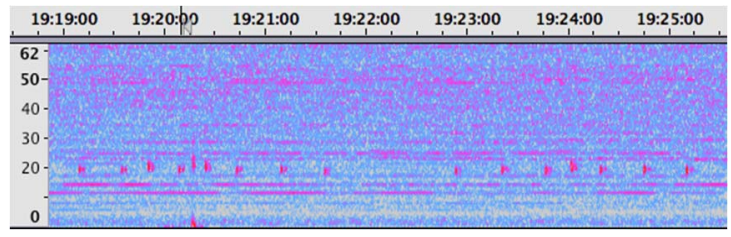

Fig. 15. Spectrogram of a series of bioacoustic sounds near $20 \mathrm{~Hz}$ recorded by HYDROBS (10 May 2018), likely due to a fin whale. Horizontal lines are probably the signature of a distant ship noise.

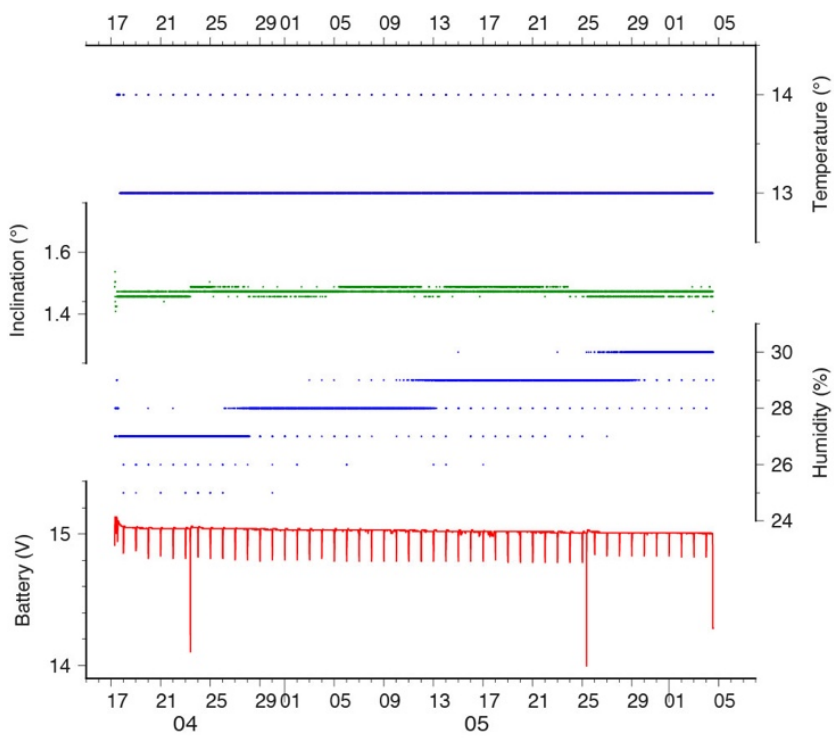

Fig. 16. Monitoring of the data-logger internal sensors of HYDROBS, sampled every 10 minutes. The battery voltage drops from $15 \mathrm{~V}$ (and the temperature increases) every time the data are duplicated in the shuttles (once a day) and when the shuttles are released (23 April, 25 May, 4 June). The battery drop is lesser after 25 May since there is only one shuttle left.

\section{MANTA Broadband OBS}

As a follow-up to the development of MUG-OBS and HYDROBS, a medium-term ocean-bottom seismometer called MANTA was developed. It combines the same data logger as HYDROBS with other features from the two platforms, such as an acoustic communication (health bulletin, installation diagnostics, release), a self-clock synchronization when surfacing, and an AIS-Iridium surface positioning. The seismometer sensor is separated from the main structure, and 
is thus directly coupled to the seafloor and shielded from bottom-current noise (Fig. 17).

MANTA acquisition system has 4 analog input channels to host a broadband or short period seismometer, and a hydrophone. An additional digital input permits to add other sensor type to complete this range of analog sensors. Rated at $6000 \mathrm{~m}$, MANTA in its standard version is equipped with a 120s broadband sensor (Trillium-OBS or Guralp Radian) a Hydrophone HTI-90U and a Paroscientific absolute pressure sensor. MANTA's life time is 1.5 years with a 120 s Trillium OBS compact. A tri-axial geophones unit $(2 \mathrm{~Hz}$ or $4.5 \mathrm{~Hz}$ ) can replace the broadband seismometer and will expand the lifespan for the instrument.

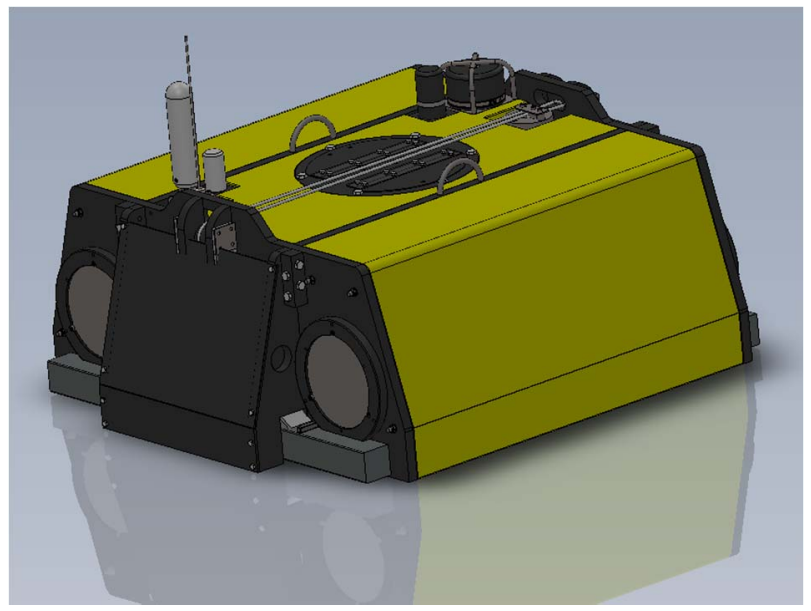

Fig. 17. MANTA OBS system. Size 100 x 100 x $60 \mathrm{~cm}$.

\section{CONCLUSION}

We presented alternative platforms for a long-term monitoring of the ocean, bridging the gap between cabled-toshore permanent stations and autonomous short-lived stations. Their concept is based on a long-term (3-4 years) main acquisition system and shuttles to retrieve the data on demand. Initially developed for seismological monitoring (MUGOBS), the system is versatile and can host other sensors (pressure gauges, oceanographic sensors), particularly in its version for mooring lines (HYDROBS).

These platforms offer innovative and key features:

- easy-to-use devices for acquiring high quality data (32-bit dynamics, adjustable sampling rate);

- shuttles releasable on demand to access the data throughout long-term deployments, saving ship-time and human resources;

- ergonomics and automation of essential tasks such as the clock-drift measurements or surface positioning, enabling non-specialists to recover the shuttles.
Both MUG-OBS and HYDROBS offer a wide range of applications for the observation of natural and anthropogenic phenomena impacting the ocean and coastal areas.

\section{ACKNOWLEDGMENT}

The development of MUG-OBS was supported by the National Research Agency (grant ANR PRIMA), the European Regional Development Fund, the Provence - Alpes - Côte d'Azur Regional Council, INSU-CNRS and IRD.

The development of HYDROBS was funded by the Regional Council of Brittany, the European Regional Development Fund, the French Government, the Finistère Department and Brest Metropole (grant CPER O3DO).

The ship-time for the MUG-OBS and HYDROBS tests was funded by the National Research Agency (ANR) through LABEX Mer in Brest, CNRS-INSU through EMSO-Ligure, and the French Oceanographic Fleet.

\section{REFERENCES}

[1] N. Jones, "Canadian earthquake detector has deep-sea edge over US rival," Nature, 534(7608), 446-447, doi:10.1038/534446a, 2016.

[2] M. Nakano et al., "Seismic activity beneath the Nankai trough revealed by DONET ocean-bottom observations", Mar. Geophys. Res., 35, doi: 10.1007/s11001-013-9195-3, 2013.

[3] D. Toomey et al., "The Cascadia Initiative: A sea change in seismological studies of subduction zones," Oceanography, 27(2),138150, doi:10.5670/oceanog.2014.49, 2014.

[4] M. Laigle et al., "Seismic structure and activity of the north-central Lesser Antilles subduction zone from an integrated approach: similarities with the Tohoku forearc", Tectonophysics, 603: 1-20, doi:10.1016/j.tecto.2013.05.043, 2013.

[5] M. Segovia, et al., "Taking the pulse of the Ecuador subduction zone near a locked patch," AGU Fall Meeting Abstract, San Francisco, 2013.

[6] S. C. Riser et al., "Fifteen years of ocean observations with the global Argo array”, Nat. Clim. Change," 6: 145-153, 2016.

[7] G. Nolet et al., "Imaging the Galápagos mantle plume with an unconventional application of floating seismometers," Sci. Rep, doi: 10.1038/s41598-018-36835-w, 2019.

[8] N. J. Lindsey et al., "Fiber-optic network observations of earthquake wavefields", Geophys. Res. Lett., 44: 11792-11799, 2017 doi: 10.1002/2017GL075722.

[9] J. B. Ajo-Franklin et al., "Distributed acoustic sensing using dark fiber for near-surface characterization and broadband seismic event detection”, Sci. Rep., doi: 10.1038/s41598-018-36675-8, 2019.

[10] D. E. McNamara and R. P. Buland, "Ambient noise levels in the continental United States", Bull. Seismol. Soc. Am., 94: 1517-1527, doi: 10.1785/012003001, 2004.

[11] J. Peterson, "Observations and modelling of background seismic noise", Open-file report 93-322, Albuquerque, New Mexico, 1993. 